\title{
PROFIL PENDERITA KANKER PAYUDARA STADIUM LANJUT BAIK LOKAL MAUPUN METASTASIS JAUH DI RSUP HASAN SADIKIN BANDUNG
}

Mochamad Aleq Sander

\author{
Fakultas Kedokteran Universitas Muhammadiyah Malang \\ Jl. Bendungan Sutami 188A Malang 65145 \\ e-mail: aleq.sander@yahoo.com \\ blog: bedahunmuh.wordpress.com
}

\begin{abstract}
Breast cancer represent one of the most second malignancy of the woman after cervix cancer. In Indonesia estimated \pm 100 new case per 100.000 population every year, meaning more or less 200.000 new case every year to all cancer type. While for the breast cancer \pm 23.140 new case every year. If breast cancer found in early stage, it has high life expectancy, ranging from $85-95 \%$. But actually $70-90 \%$ patient came to hospital after their disease were hard and advanced stage. Cancer medication at advanced stage was very difficult and its result very dissatisfactory. The aim of research is to know the epidemiology, clinical symptom, diagnosis, therapy, prognosis. Descriptive study with retrospective design. Total sampling was all outpatient in oncology deparment of Hasan Sadikin Hospital of Bandung with advanced stadium of breast cancer from January 2003 up to December 2008. 164 eligible respondens who had age below 35 yo 28 (17.1\%) and above 35 yo 136 (82.9\%). Average of menarche 11.77 yo. Location of right breast cancer 78 (47.6\%), left $82(50 \%)$, and both $4(2.4 \%)$. A lot of stadium was T4bNoMx that is 18 (11\%). Chest x-ray, laboratory, and USG were the most diagnostic procedure often used that is 19 (11.6\%). The most common therapy was BE $+V C+R M$ that is 17 (10.4\%). The prognosis was healing 20 (12.2\%), not/not yet healed $30(18.3 \%)$, not control 110 (67.1\%), and who control in the other place 4 (2.4\%). Conclusion was mostly diagnosis of breast cancer according to anatomy pathology, chest x-ray, laboratory, and ultrasonografi. A lot of breast cancer location was left side. Excision biopsy, and followed by radical mastectomy were the most therapy procedure. Therapy evaluation to assess the level of healing was difficult because most patient did not conduct the control after therapy.
\end{abstract}

Keywords: breast cancer, locally advanced and advanced stage

Abstrak

Kanker payudara adalah keganasan kedua terbanyak pada wanita setelah kanker leher rahim. Di Indonesia diperkirakan ada 100 kasus baru tiap 100.000 penduduk tiap tahunnya, artinya bahwa \pm 200.000 kasus baru tiap tahun untuk semua kasus kanker. Sementara untuk kanker payudara terdapat \pm 23.140 kasus baru tiap tahun. Jika kanker payudara ditemukan pada stadium awal maka pasien akan memiliki harapan hidup tinggi antara 85-95\%. Tetapi kenyataannya bahwa 70-90\% penderita datang ke rumah sakit sudah dalam stadium lanjut. Pengobatan kanker payudara pada stadium lanjut sangat sulit dan tidak memuaskan. Penelitian ini bertujuan untuk mengetahui epidemiologi, gejala klinis, cara diagnosis, macam terapi, dan prognosis penderita kanker payudara stadium lanjut serta didesain sebagai penelitian deskriptif retrospektif. Teknik sampling menggunakan total sampling yaitu penderita kanker payudara stadium lanjut di poliklinik Bedah Onkologi RSUP Hasan Sadikin Bandung dari Januari tahun 2003 - Desember 
2008. Ada 164 sampel yang eligible, dimana yang berusia dibawah 35 tahun 28 (17.1\%) dan diatas 35 tahun 136 (82.9\%). Usia rerata menarche 11.77 tahun. Lokasi kanker payudara kanan 78 (47.6\%), payudara kiri 82 (50\%), dan kedua payudara 4 (2.4\%). Stadium terbanyak T4bNoMx yaitu 18 (11\%). Foto ronsen dada, laboratorium, dan USG adalah prosedur diagnostik yang paling sering digunakan yaitu $19(11.6 \%)$. Paket terapi yang paling sering adalah $\mathrm{BE}+\mathrm{VC}+\mathrm{RM}$ yaitu 17 (10.4\%). Prognosis didapatkan sembuh 20 (12.2\%), tidak/belum sembuh 30 (18.3\%), tidak kontrol 110 (67.1\%), dan yang kontrol ditempat lain 4 (2.4\%). Kesimpulan dari penelitian adalah bahwa sebagian besar diagnosis kanker payudara berdasarkan hasil PA, foto ronsen dada, laboratorium, dan USG. Lokasi terbanyak adalah payudara kiri. Biopsi eksisi (BE), vries coup (VC), dan dilanjutkan radikal mastektomi (RM) adalah prosedur terapi yang paling banyak diterapkan. Evaluasi terapi untuk menilai tingkat kesembuhan sulit dilakukan karena kebanyakan penderita tidak melakukan kontrol pasca terapi.

Kata kunci: kanker payudara, stadium lokal lanjut dan metastasis jauh

\section{LATAR BELAKANG}

Kanker payudara adalah suatu penyakit neoplasma ganas yang berasal atau tumbuh di dalam struktur saluran dan kelenjar payudara. Penyakit ini oleh WHO dimasukkan ke dalam International Classification of Diseases (ICD) dengan kode nomor 174 (Robin et al, 2005).

Kanker payudara merupakan kanker terbanyak kedua sesudah kanker leher rahim di Indonesia. Selain jumlah kasus yang banyak, lebih dari $70 \%$ penderita kanker payudara ditemukan pada stadium lanjut. Data dari Direktorat Jenderal Pelayanan Medik Departemen Kesehatan menunjukkan bahwa Case Fatality Rate (CFR) akibat kanker payudara menurut golongan penyebab sakit menunjukkan peningkatan dari tahun 1992-1993, yaitu dari 3,9 menjadi 7,8 (Moningkey et al, 2000).

Kanker payudara jarang berkembang sebelum umur 25 tahun, insidens tertinggi pada masa perimenopause. Lebih sering terjadi pada pasien dengan riwayat kanker payudara dalam keluarga, risiko meningkat secara proporsional dengan jumlah anggota tingkat pertama yang menderita kanker (Robin et al, 2005).

Sampai saat ini, penyebab kanker payudara belum diketahui secara pasti.
Penyebab kanker payudara termasuk multifaktorial, yaitu banyak faktor yang terkait satu dengan yang lain. Beberapa faktor yang diperkirakan mempunyai pengaruh besar dalam terjadinya kanker payudara adalah reproduksi (nultipara, menarche dini, menopause lama, dan hamil pertama usia tua), hormonal, penyakit fibrokistik, obesitas, riwayat radiasi, riwayat keluarga, dan faktor lain yang bersifat eksogen (Robin et al, 2005).

Gejala klinis kanker payudara dapat berupa benjolan pada payudara, erosi atau eksema puting susu, atau pendarahan puting susu. Umumnya benjolan tidak nyeri dan awalnya kecil, makin lama makin besar, lalu melekat pada kulit atau puting susu. Puting susu menjadi tertarik ke dalam (retracted nipple), kulit oedema hingga tampak seperti kulit jeruk (peau d'orange), mengkerut, atau timbul borok (ulcus) pada payudara. Borok itu makin lama makin besar dan dalam sehingga menghancurkan seluruh payudara, sering berbau busuk, dan mudah berdarah. Rasa sakit atau nyeri pada umumnya baru timbul bila tumor sudah besar, timbul borok, atau ada metastasis ke tulang. Kemudian timbul pembesaran kelenjar getah bening di ketiak, bengkak (edema) pada lengan, dan penyebaran kanker ke seluruh tubuh (Tjindarbumi, 2000). 
Kanker payudara lanjut sangat mudah dikenali dengan mengetahui kriteria operabilitas Heagensen sebagai berikut: terdapat edema luas pada kulit payudara (lebih 1/3 luas kulit payudara); adanya nodul satelit pada kulit payudara; kanker payudara jenis mastitis karsinomatosis; terdapat nodul parasternal; terdapat nodul supraklavikula; adanya edema lengan; adanya metastasis jauh; serta terdapat dua dari tanda-tanda locally advanced, yaitu ulserasi kulit, edema kulit, kulit terfiksasi pada dinding toraks, kelenjar getah bening aksila berdiameter lebih 2,5 cm, dan kelenjar getah bening aksila melekat satu sama lain (Brunicardi et al, 2010).

Dari seluruh kanker payudara, sekitar 50\% tumbuh pada kuadran lateral atas, $10 \%$ pada ketiga kuadran yang lain, dan $20 \%$ di regio subareolar. Lesi multifokal (misalnya yang timbul pada kuadran lain di luar massa tumor utama) pada kurang lebih sepertiga pasien dan tidak jarang bilateral, khususnya pada varian lobular karsinoma payudara . Sebagian besar kanker payudara terjadi pada unit duktus terminal (kecuali yang menjadi penyakit Paget dan karsinorna lobuler) dan perbedaan di antara tipe-tipe variasinya, yang mempunyai gambaran patologi klinik tertentu, didasarkan pada gambaran sitologik dan arsitektur individual (Tjindarbumi, 2000).

Seluruh kanker payudara kecuali tipe medulare harus dibuat gradasi histologisnya. Sistim gradasi histologis yang direkomendasikan adalah menurut "The Nottingham combined histologic grade" (menurut Elston-Ettis yang merupakan modifikasi dari Bloom-Richardson) (Manuaba TW, 2010). Gradasinya adalah sebagai berikut:

Gx : Grading tidak dapat dinilai.

G1 : Low grade (rendah).

G2 : Intermediate grade (sedang).

G3 : High grade (tinggi).
Klasifikasi stadium berdasarkan sistem TNM dari AJCC 2002 adalah sebagai berikut (Manuaba TW, 2010):

$\mathrm{T}=$ ukuran tumor primer

Tx : Tumor primer tidak dapat dinilai.

T0 : Tidak terdapat tumor primer.

Tis : Karsinoma in situ.

Tis (DCIS): Ductal carcinoma in situ.

Tis (LCIS): Lobular carcinoma in situ.

Tis (Paget): Penyakit Paget pada puting tanpa adanya tumor.

T1 : Tumor dengan ukuran diameter d" $2 \mathrm{~cm}$.

T2 : Tumor dengan ukuran diameter 2$5 \mathrm{~cm}$.

T3 : Tumor dengan ukuran diameter > $5 \mathrm{~cm}$.

T4 : Ukuran tumor berapapun dengan ekstensi langsung ke dinding dada atau kulit.

Catatan:

Dinding dada adalah termasuk iga, otot interkostalis, dan serratus anterior tapi tidak termasuk otot pektoralis.

T4a : Ekstensi ke dinding dada.

T4b : Ekstensi ke kulit yang terbatas pada 1 payudara.

T4c : Mencakup kedua hal diatas.

T4d : Mastitis karsinomatosis.

$\mathrm{N}=$ kelenjar getah bening regional (KGB).

$\mathrm{Nx} \quad$ : KGB regional tidak bisa dinilai (telah diangkat sebelumnya).

N0 :Tidak terdapat metastasis KGB.

N1 : Metastasis ke KGB aksila ipsilateral yang mobil.

N2 : Metastasis ke KGB aksila ipsilateral terfiksir, berkonglomerasi, atau adanya pembesaran KGB mamaria interna ipsilateral (klinis*) tanpa adanya metastasis ke KGB aksila.

N3 :Metastasis pada KGB infraklavikular ipsilateral dengan atau tanpa metastasis KGB aksila atau klinis terdapat metastasis pada KGB mamaria interna ipsilateral klinis dan metastasis 
pada KGB aksila; atau metastasis pada KGB supraklavikula ipsilateral dengan atau tanpa metastasis pada KGB aksila/ mamaria interna.

N3a :Metastasis ke KGB infraklavikular ipsilateral.

N3b :Metastasis ke KGB mamaria interna dan KGB aksila.

N3c :Metastasis ke KGB supraklavikula.

Catatan:

* Terdeteksi secara klinis: terdeteksi dengan pemeriksaan fisik atau secara imaging (diluar limfoscintigrafi).

$\mathrm{M}:$ metastasis jauh

Mx :Metastasis jauh belum dapat dinilai.

M0 :Tidak terdapat metastasis jauh.

M1 :Terdapat metastasis jauh.

Gambaran yang umum pada semua karsinoma invasif adalah sebagai berikut:

1. Invasi lokal ke dalam struktur penunjang menyebabkan tumor terfiksasi, retraksi puting, dan dimpling pada kulit. Invasi pada sistem limfatik berhubungan dengan metastasis ke kelenjar limfe, dan bila meluas ke kulit akibat limfedema, menyebabkan kulit payudara menyerupai kulit jeruk (peau d'orange atau karsinoma inflamatoir). Mikrokalsifikasi yang dideteksi dengan mamografi pada atau berkaitan dengan karsinoma dicatat pada sekitar $60 \%$ kasus. Sayangnya banyak lesi jinak yang juga menunjukkan mikrokalsifikasi.

2. Sekitar dua pertiga kanker payudara ditemukan dengan metastasis pada KGB. Meskipun semua kanker payudara dapat bermetastasis ke kelenjar aksila, supraklavikula, dan/atau mamaria interna, tumor yang terletak pada kuadran lateral cenderung bermetastasis ke kelenjar aksila, sedangkan tumor di kuadran medial dan sentral payudara cenderung bermetastasis ke kelenjar mamaria interna. Tempat penyebaran lain yang disukai adalah kulit, tulang, paruparu, hati, dan adrenal.

Prosedur diagnostik untuk kanker payudara meliputi (Manuaba TW, 2010):

A. Pemeriksaan Klinis

1. Anamnesis:

- Keluhan di payudara atau ketiak dan riwayat penyakitnya, antara lain: benjolan, kecepatan tumbuh, rasa sakit, nipple discharge, retracted nipple, krusta pada areola, kelainan kulit (dimpling, peau d'orange, ulserasi, venektasi), benjolan ketiak, edema lengan.

- Keluhan ditempat lain berhubungan dengan metastasis, antara lain: nyeri tulang (vertebra dan femur), rasa penuh di ulu hati, batuk, sesak, sakit kepala hebat, dll.

- Faktor-faktor resiko, antara lain: usia penderita, usia melahirkan anak pertama, punya anak atau tidak, riwayat menyusukan, riwayat menstruasi (usia menarche dan menopause), riwayat pemakaian obat hormonal, riwayat keluarga sehubungan dengan kanker payudara atau kanker lain, riwayat pernah operasi tumor payudara atau tumor ginekologik, riwayat radiasi dinding dada.

2. Pemeriksaan fisik

a. Status generalis, cantumkan performance status.

b. Status lokalis:

- Payudara kanan dan kiri harus diperiksa

- Masa tumor, terdiri dari: lokasi, ukuran, konsistensi, permukaan, bentuk dan batas tumor, jumlah tumor, terfiksasi atau tidak ke jaringan mama sekitar, kulit, otot dinding dada.

- Perubahan kulit: kemerahan, dimpling, edema, nodul satelit, peau d'orange, ulserasi

- Nipple: tertarik, erosi, krusta, discharge.

- Status KGB aksila, infraklavikula, dan supraklavikula: Jumlah, ukuran, 
konsistensi, terfiksir satu sama lain atau jaringan sekitar.

- Pemeriksaan pada daerah yang dicurigai metastasis: lokasi organ (paru, tulang, hepar, dan otak)

B. Pemeriksaan Imaging:

1. Diharuskan (recommended)

- USG payudara dan Mamografi untuk tumor d" $3 \mathrm{~cm}$

- Foto Toraks

- USG Abdomen

2. Optional (atas indikasi)

- Bone scanning atau dan bone survey (bilamana sitologi + atau klinis sangat mencurigai pada lesi $>5 \mathrm{~cm}$ )

- CT scan

C.Pemeriksaan Histopatologik (Gold Standard Diagnostic)

Pemeriksaan dilakukan dengan potong beku dan/atau paraffin dengan bahan diambil melalui:

- Core Biopsy

- Biopsi eksisi (BE) untuk tumor $<3 \mathrm{~cm}$

- Biopsi insisi (BI) untuk tumor operable $>3 \mathrm{~cm}$ sebelum operasi definitif dan inoperable

- Spesimen mastektomi disertai dengan pemeriksaan kelenjar getah bening.

Pemeriksaan imunohistokimia ER, PR, c-erb B-2 (HER-2 neu), cathepsin-D, p53 bersifat optional.

Metode penyaringan (screening) pada kanker payudara perlu dilakukan pada wanita yang masih mengalami menstruasi dan berisiko tinggi, yaitu dengan cara:

1. SADARI (Pemeriksaan Payudara Sendiri)

Dilaksanakan pada wanita mulai usia subur, setiap 1 minggu setelah hari pertama menstruasi terakhir.

2. Pemeriksaan Fisik dilakukan oleh dokter secara lige-artis.

3. Mamografi

- Pada wanita 35-50 tahun: setiap 2 tahun.

- Pada wanita > 50 tahun: setiap 1 tahun.
Pada daerah yang tidak ada mamografi ataupun fasilitas USG, untuk deteksi dini dilakukan dengan SADARI dan pemeriksaan fisik saja.

Modalitas terapi kanker payudara meliputi: operasi, radiasi, kemoterapi, hormonal, dan molecular targeting therapy (biology therapy).

1. Operasi:

- BCS (Breast Conserving Surgery).

- Simpel mastectomy.

- Modified radical mastectomy.

- Radical mastectomy.

2. Radiasi: primer, adjuvant, dan paliatif.

3. Kemoterapi: kombinasi dari beberapa obat dengan regimen sebagai berikut:

- AC (adriamycin, cyclofosfamid)

- EC (epirubicin, cyclofosfamid)

- CMF (cyclofosfamid, metothrexate, fluorouracil)

- CAF (cyclofosfamid, adriamycin, fluorouracil)

- CEF (cyclofosfamid, epirubicin, fluorouracil

- Taxane + Doxorubicin

- Capecetabin.

4. Hormonal:

- Ablative : bilateral Oovorectomy.

- Additive: Tamoxifen.

- Optional : Aromatase inhibitor, GnRH (Gonadotropin Releasing Hormone)

Untuk penanganan kanker payudara locally advanced (lokal lanjut), terdiri dari:

1. Operable locally advanced

- Simple mastectomy/MRM + radiasi kuratif + kemoterapi adjuvant + hormonal.

2. Inoperable Locally advanced

- Radiasi kuratif + kemoterapi + hormonal

- Radiasi + operasi + kemoterapi + hormonal

- Kemoterapi neo-adjuvant + operasi + kemoterapi + radiasi + hormonal. 
Sedangkan untuk kanker payudara yang sudah mengalami metastasis jauh, prinsip penanganannya sebagai berikut:

1. Sifat terapi paliatif

2. Terapi sistemik merupakan terapi primer (kemoterapi dan hormonal)

3. Terapi lokoregional (radiasi dan bedah) hanya apabila diperlukan untuk mengurangi massa tumor dan bau yang tidak pada borok kanker payudara.

\section{METODE}

Penelitian ini adalah deskriptif retrospektif yang dilakukan di Sub Bagian Bedah Onkologi RSUP Hasan Sadikin Bandung dengan teknik sampling berupa total sampling dari status rekam medik penderita kanker payudara stadium lanjut baik lokal maupun metastasis jauh yang ada di poliklinik Bedah Onkologi RSUP Hasan Sadikin Bandung dari tanggal 1 Januari 2003 - 31 Desember 2008 yang telah terdiagnosis pasti dengan hasil PA. Kriteria inklusi sebagai berikut:

1. Pasien kanker payudara stadium III A, IIIB, dan IV berdasarkan sistem TNM/ AJCC 2002.

2. Pasien kanker payudara yang telah didiagnosis melalui pemeriksaan histopatologi.

3. Pasien kanker payudara yang di work-up sejak awal di RSUP Hasan Sadikin Bandung.

4. Status lengkap berada dibagian rekam medik poli rawat jalan RSUP Hasan Sadikin Bandung.

Data yang diperoleh dari status rekam medik dideskripsikan dan kemudian dianalisis serta dihitung persentasenya. Data yang telah dihitung selanjutnya disusun ke dalam grafik. Hasil analisis data dalam penelitian ini dilakukan dengan cara tabulasi dengan tabel deskriptif.

\section{HASIL DAN PEMBAHASAN}

Diperoleh sampel sebanyak 387 penderita yang terdiagnosis sebagai kanker payudara, tetapi hanya 164 penderita yang memenuhi kriteria penelitian.

A. Karakteristik Respondens

A.1 Karakteristik Usia

Penderita diatas 36 tahun sebanyak 136 kasus $(82.9 \%)$ dan dibawah 35 tahun ada 28 kasus (17.1\%) (gambar 2). Penderita terbanyak usia 46 tahun yaitu 11 kasus $(6.7 \%)$ (gambar 1). Usia ratarata 47.11 tahun dengan standar deviasi \pm 11.16 . Hal ini sesuai dengan Brunicardi et al dan Robbins et al, yaitu bahwa risiko utama kanker payudara adalah bertambahnya usia. Kurang dari 25\% kanker payudara terjadi pada masa sebelum menopause. Apabila pada penderita terdapat gen BRCA-1, yaitu suatu gen suseptibilitas kanker payudara, probabilitas terjadinya kanker payudara $60 \%$ pada usia 50 tahun dan $85 \%$ pada usia 70 tahun.

\section{A.2 Karakteristik Usia Menarche}

Usia menarche paling banyak dibawah 13 tahun yaitu 133 kasus (81.1\%) (gambar 4). Puncak usia menarche 12 tahun yaitu 35 kasus (21.3\%) (gambar 3). Rata-rata menarche adalah 11.77 tahun dengan standar deviasi \pm 1.87 . Hal ini sesuai dengan Robins et al, bahwa risiko terjadinya kanker payudara adalah menarche pada usia muda, dimana hal ini akan memperlama waktu paparan hormon estrogen baik endogen maupun eksogen yang pada akhirnya memicu terjadinya proliferasi yang berlebihan pada sel-sel payudara.

\section{A.3 Karakteristik Usia Menopause}

Ada 66 kasus (40.2\%) sudah menopause dan 98 kasus (59.8\%) masih menstruasi (gambar 6). Usia menopause terbanyak adalah 51 tahun yaitu 16 kasus (9.8\%) (gambar 5). Rata-rata menopause adalah 51.39 tahun dengan standar deviasi \pm 2.47 . Hal ini sesuai Robins et al bahwa risiko terjadinya kanker payudara adalah menopause 


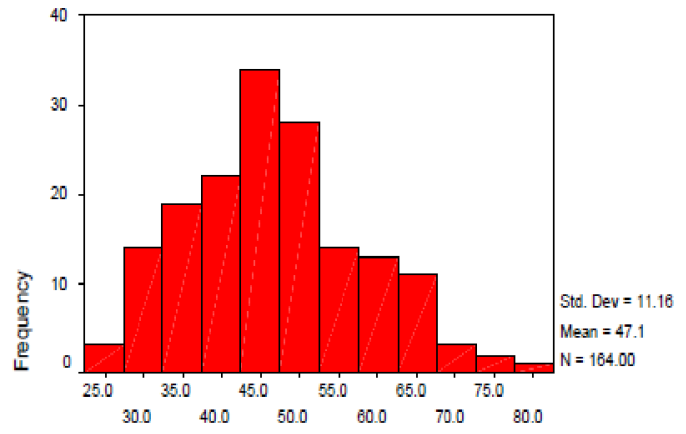

umur respondens

Gambar 1. Sampel menurut usia

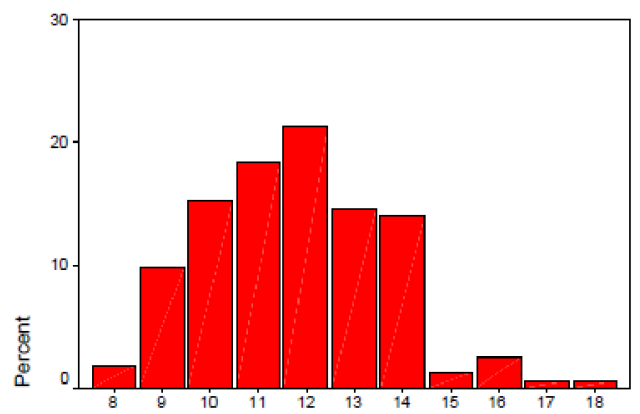

usia menarche

Gambar 3. Sampel menurut usia menarche

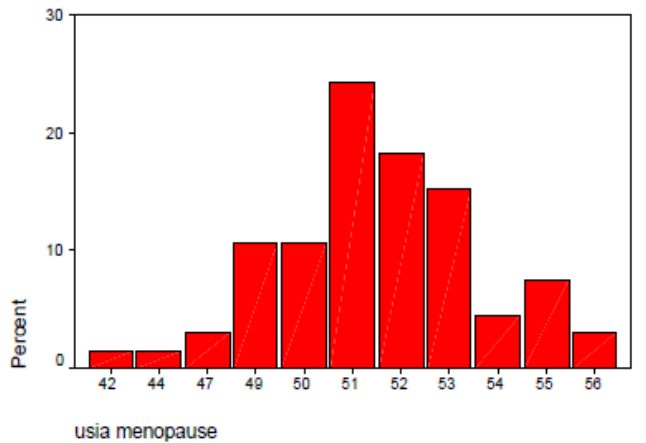

Gambar 5. Sampel menurut usia menopause

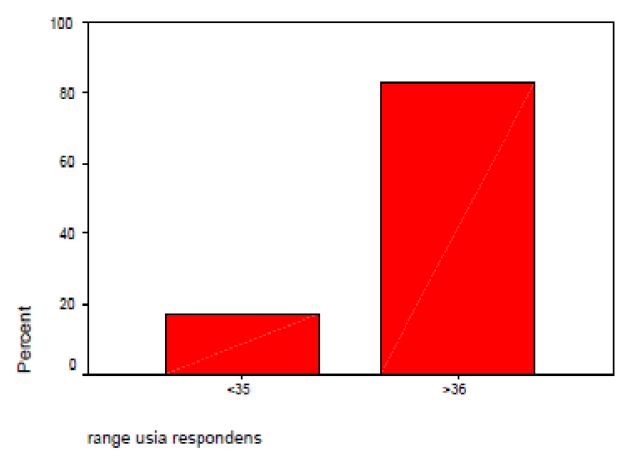

Gambar 2. Sampel menurut range usia

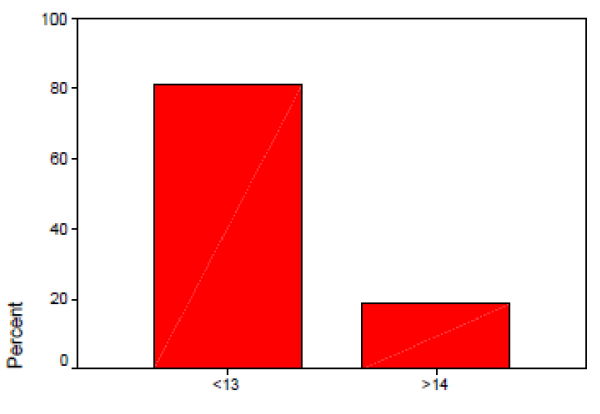

range usia menarche

Gambar 4. Sampel menurut range usia menarche

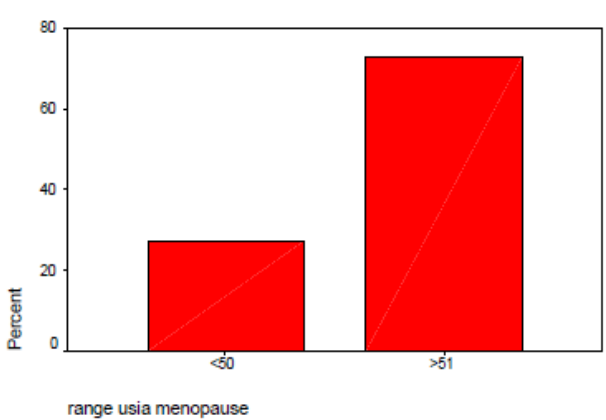

Gambar 6. Sampel menurut range usia menopause

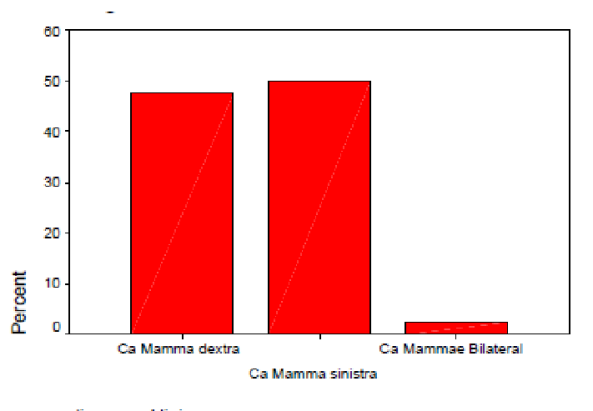

diagnosa klinis

Gambar 6. Sampel menurut diagnosis klinis 


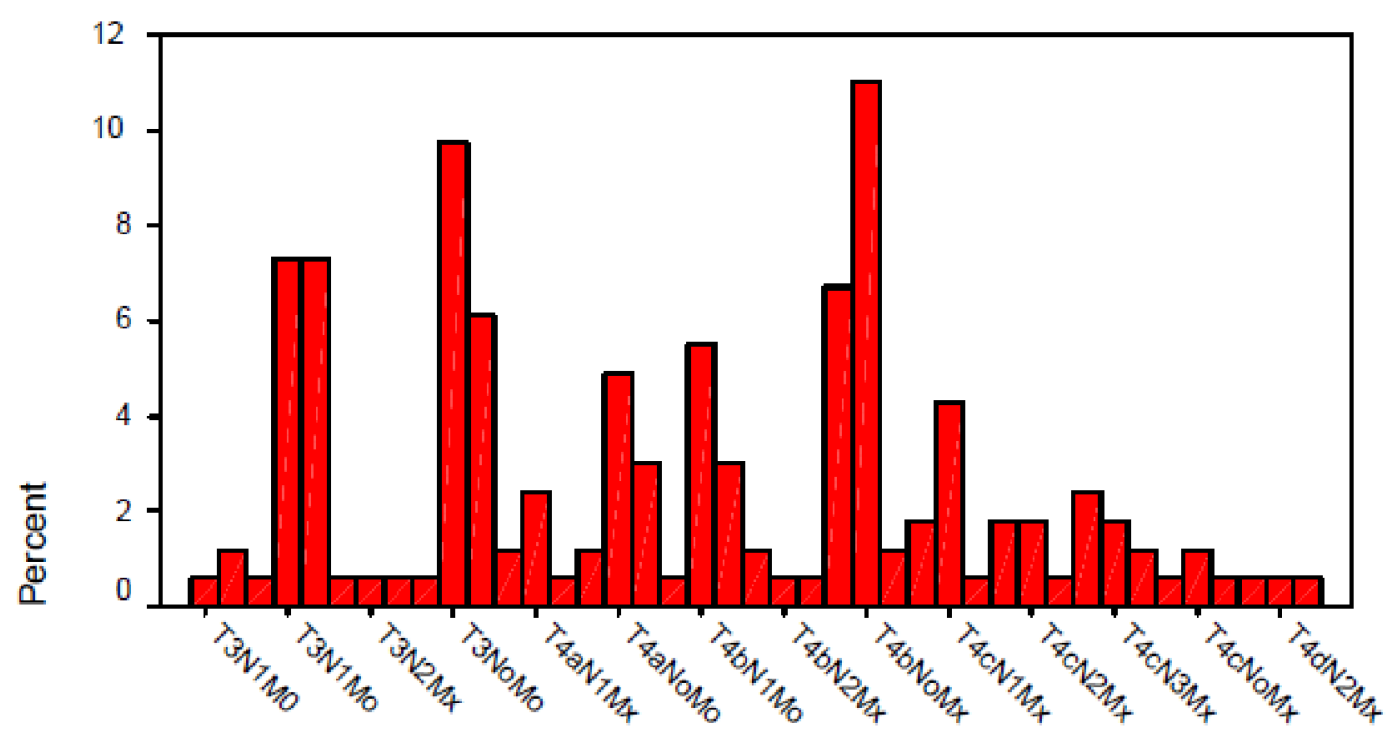

stadium ca mamma

Gambar 7. Sampel menurut stadium klinis

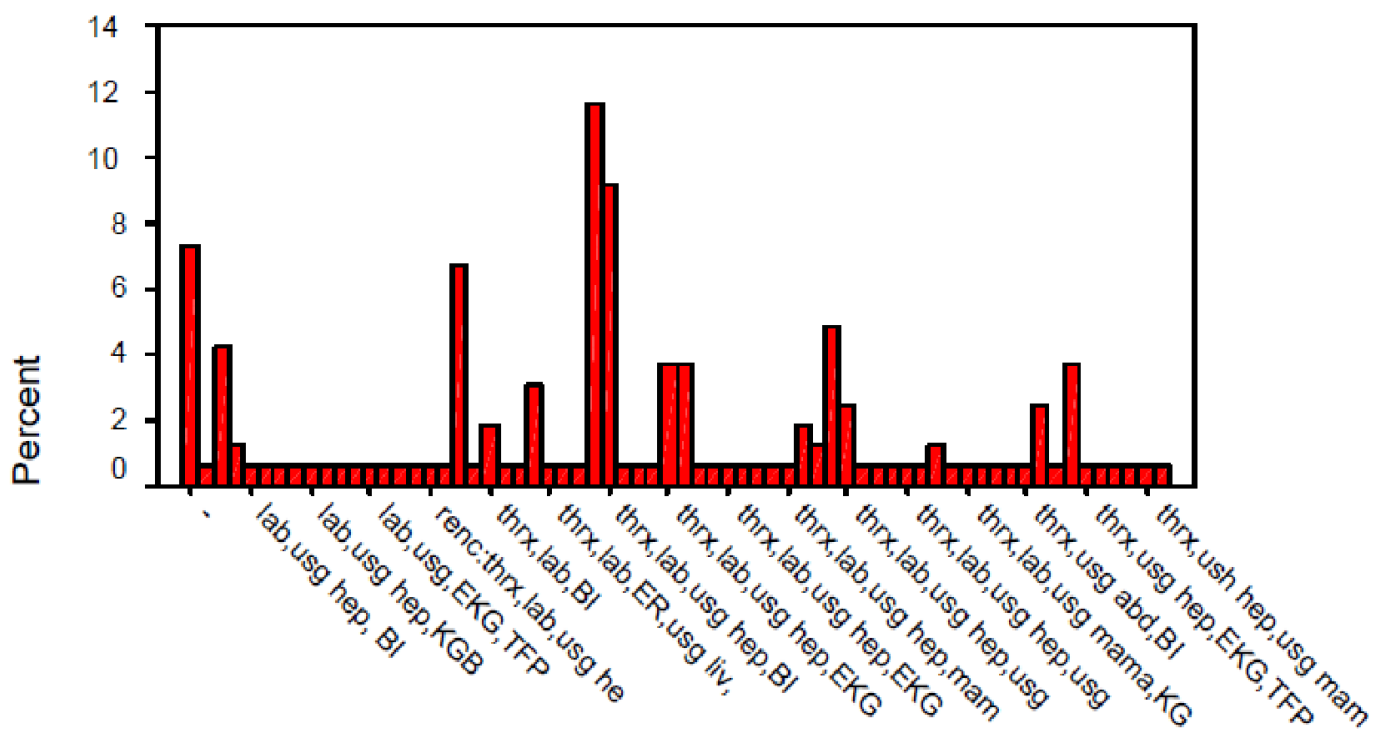

Gambar 8. Sampel menurut prosedur diagnosis

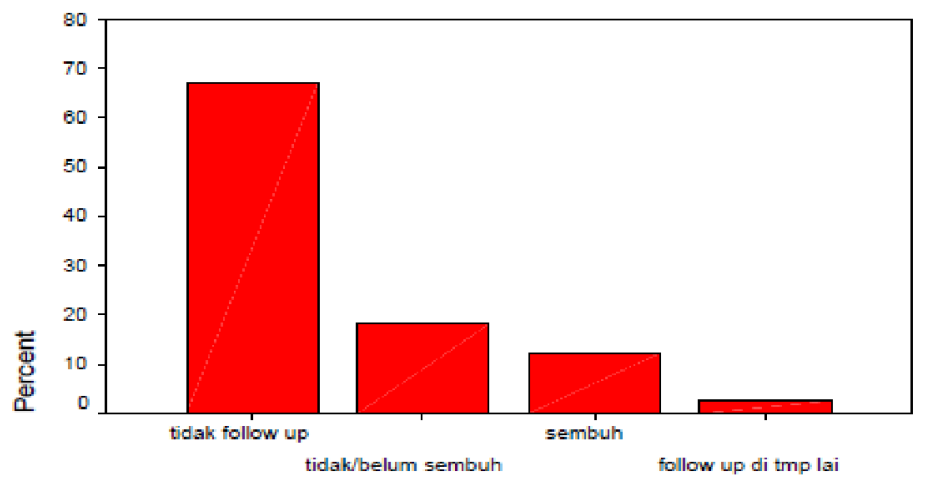

Gambar 9. Sampel menurut prognosis 
Tabel 1. Sebaran sampel berdasarkan prosedur terapi

\begin{tabular}{|c|c|c|c|c|c|}
\hline & & Frequency & Percent & $\begin{array}{c}\text { Valid } \\
\text { Percent }\end{array}$ & $\begin{array}{c}\text { Cumulative } \\
\text { Percent }\end{array}$ \\
\hline \multirow[t]{2}{*}{ Valid } & - & 54 & 32.9 & 32.9 & 32.9 \\
\hline & BE+VC,MRM & 1 & .6 & .6 & 33.5 \\
\hline & $\mathrm{BE}+\mathrm{VC}, \mathrm{MRM}$,kemoterapi & 1 & .6 & .6 & 34.1 \\
\hline & $\mathrm{BE}+\mathrm{VC}$, radioterapi & 2 & 1.2 & 1.2 & 35.4 \\
\hline & $\mathrm{BE}+\mathrm{VC}$, radioterapi, $\mathrm{MRM}$, renc:kemotx & 1 & .6 & .6 & 36.0 \\
\hline & $\mathrm{BE}+\mathrm{VC}$, renc:RM & 1 & .6 & .6 & 36.6 \\
\hline & $\mathrm{BE}+\mathrm{VC}, \mathrm{RM}$ & 17 & 10.4 & 10.4 & 47.0 \\
\hline & $\mathrm{BE}+\mathrm{VC}, \mathrm{SM}$ & 4 & 2.4 & 2.4 & 49.4 \\
\hline & $\mathrm{BE}+\mathrm{VC}, \mathrm{SM}$,radioterapi & 1 & .6 & .6 & 50.0 \\
\hline & Incisi Drainage & 1 & .6 & .6 & 50.6 \\
\hline & Kemoterapi & 5 & 3.0 & 3.0 & 53.7 \\
\hline & MRM & 1 & .6 & .6 & 54.3 \\
\hline & MRM,kemoterapi & 1 & .6 & .6 & 54.9 \\
\hline & Radioterapi & 15 & 9.1 & 9.1 & 64.0 \\
\hline & radioterapi,hectng & 1 & .6 & .6 & 64.6 \\
\hline & radioterapi,renc:kemoterapi & 1 & .6 & .6 & 65.2 \\
\hline & radioterapi,renc:RM & 1 & .6 & .6 & 65.9 \\
\hline & radioterapi,renc:RM sekunder & 1 & .6 & .6 & 66.5 \\
\hline & radioterapi,RM & 4 & 2.4 & 2.4 & 68.9 \\
\hline & radioterapi,RM,kemoterapi & 2 & 1.2 & 1.2 & 70.1 \\
\hline & radioterapi,SM & 1 & .6 & .6 & 70.7 \\
\hline & renc: BE & 1 & .6 & .6 & 71.3 \\
\hline & renc: radioterapi & 1 & .6 & .6 & 72.0 \\
\hline & renc:BE+VC & 8 & 4.9 & 4.9 & 76.8 \\
\hline & renc:Bl & 1 & .6 & .6 & 77.4 \\
\hline & renc:echocardiography & 1 & .6 & .6 & 78.0 \\
\hline & renc:kemoterapi & 9 & 5.5 & 5.5 & 83.5 \\
\hline & renc:kemoterapi, RM & 1 & .6 & .6 & 84.1 \\
\hline & renc:MRM & 1 & .6 & .6 & 84.8 \\
\hline & renc:radioterapi & 12 & 7.3 & 7.3 & 92.1 \\
\hline & renc:radioterapi, $\mathrm{RM}$ & 1 & .6 & .6 & 92.7 \\
\hline & renc: RM & 2 & 1.2 & 1.2 & 93.9 \\
\hline & RM & 5 & 3.0 & 3.0 & 97.0 \\
\hline & RM,kemoterapi & 2 & 1.2 & 1.2 & 98.2 \\
\hline & RM,radioterapi & 1 & .6 & .6 & 98.8 \\
\hline & RM,renc:kemoterapi & 1 & .6 & .6 & 99.4 \\
\hline & SM & 1 & .6 & .6 & 100.0 \\
\hline & Total & 164 & 100.0 & 100.0 & \\
\hline
\end{tabular}

pada usia lebih tua, dimana hal ini akan memperlama waktu paparan hormon estrogen baik endogen maupun eksogen yang pada akhirnya memicu terjadinya proliferasi yang berlebihan pada sel-sel payudara.
A.4 Karakteristik Diagnosis Klinis

Lokasi terbanyak adalah payudara kiri yaitu 82 kasus (50\%), payudara kanan 78 kasus (47.6\%), dan kanker di kedua payudara hanya 4 kasus $(2.4 \%)$ (gambar 6). 


\section{A.5 Karakteristik Stadium Klinis}

Stadium klinis terbanyak adalah T4bN0Mx yaitu 18 kasus (11\%), dimana menurut klasifikasi TNM (AJCC) 2002 tumor digambarkan sebagai berikut: 1) T4b adalah ukuran tumor berapapun dengan ekstensi ke dinding dada/kulit, terdapat edema (termasuk peau d'orange), ulserasi, nodul satelit pada kulit yang terbatas pada 1 payudara, 2) N0 adalah tidak ada metastasis ke kelenjar getah bening, 3) Mx menunjukkan metastasis jauh belum bisa dinilai.

Mengapa metastasis belum bisa dinilai, hal ini semata-mata karena sebagian besar penderita tidak melakukan kontrol ke poli onkologi RSHS Bandung, sehingga pemeriksan saringan yang harus dikerjakan tidak bisa dilakukan. Mengenai mengapa penderita tidak kontrol lagi tidak ada keterangan dalam status rekam medis penderita.

\section{A.6 Karakteristik Prosedur Diagnosis} Pemeriksaan yang sering dilakukan adalah gabungan antara foto toraks, laboratorium, dan USG hepar yaitu 19 kasus (11.6\%) (gambar 8). Ada 12 kasus (7.3\%) dimana pada status rekam medis penderita tidak ditemukan jenis-jenis pemeriksaan yang dilakukan pada pasien. Hal ini disebabkan karena penderita tidak melakukan kontrol setelah kunjungan pertamanya.

\section{A.7 Karakteristik Prosedur Terapi}

Prosedur terapi yang sering dilakukan adalah biopsi eksisi (BE) dengan vries coup (VC) yang dilanjutkan dengan tindakan radical mastectomy (RM) atau modified radical mastectomy (MRM) yaitu 17 kasus (10.4\%), sedangkan modalitas radioterapi menduduki peringkat kedua yaitu 15 kasus $(9.1 \%)$ (tabel 1). Ada 54 kasus (32.9\%) yang setelah diteliti tidak ada jenis modalitas terapi yang dilakukan, hal ini disebabkan karena penderita tidak melakukan kontrol lagi untuk dilakukan pemberian modalitas terapi berdasarkan keadaan klinis yang ada.

A.8 Karakteristik Prognosis

Ada 110 kasus (67.1\%) tidak melakukan kontrol ke poli onkologi RSHS Bandung, 30 kasus (18.3\%) yang ketika kontrol dinyatakan belum atau tidak sembuh, dan 20 kasus (12.2\%) dinyatakan sembuh sedangkan sisanya sebanyak 4 kasus (2.4\%) melakukan kontrol di tempat lain (gambar 9).

Mengenai mengapa penderita kanker payudara tidak melakukan kontrol lagi, tidak ada keterangan yang jelas pada status rekam medis mereka.

\section{KESIMPULAN}

1. Jumlah kanker payudara cenderung meningkat setiap tahunnya dalam kurun waktu 5 tahun.

2. Kanker payudara banyak ditemukan pada golongan usia diatas 36 tahun.

3. Usia menarche diatas 14 tahun menduduki porsi terbanyak pada penderita kanker payudara.

4. Sebagian besar penderita kanker payudara masih mengalami menstruasi.

5. Kanker payudara kiri menduduki peringkat terbanyak dari segi lokasi tumor.

6. Stadium T4bNOMx adalah stadium terbanyak.

7. Prosedur diagnostik terbanyak adalah foto toraks, laboratorium, dan USG hepar.

8. Prosedur terapi yang sering diterapkan adalah $\mathrm{BE}+\mathrm{VC}+\mathrm{RM} /$ MRM

9. Sebagian besar pasien tidak melakukan kontrol lagi ke poli onkologi RSHS Bandung baik setelah dilakukan pemeriksaan fisik ataupun saat akan di 
jadwalkan untuk pemberian modalitas terapi.

\section{SARAN}

1. Perlu upaya pemberian informasi yang jelas dan mudah dimengerti kepada penderita kanker payudara mengenai:

a. Faktor risiko terjadinya penyakit kanker payudara.

b. Gejala-gejala awal penyakit kanker payudara sehingga penderita tidak datang ketika penyakitnya sudah melewati stadium lanjut.

c. Pentingnya pemeriksaan saringan terhadap wanita terutama yang berusia diatas 35 tahun.

d. Pentingnya melakukan kontrol rutin guna penyembuhan yang paripurna.

2. Perlunya mengadakan sistem pencatatan rekam medis yang lebih lengkap dan konsisten guna kepentingan pihak rumah sakit, penderita kanker payudara, dan untuk penelitian.

\section{DAFTAR PUSTAKA}

1. Moningkey, Shirley I. 2000. Epidemiologi Kanker Payudara. Jakarta: Medika.

2. Manuaba TW. 2010. Panduan Penatalaksanaan Kanker Solid Peraboi. Bandung: Sagung Seto.

3. Robbins S, Cotran R. 2005. Pathologic Basis of Disease. $7^{\text {th }}$ edition. International Edition. Pennsylvania: Elsevier.

4. Brunicardi FC, Anderson DK, Billiar TR, Dunn DL, Hunter JG, Matthews JB et al. 2010. Schwartz's Principles of Surgery. $9^{\text {th }}$ edition. The united states of America: The McGrawHill Companies, Inc.

5. Tjindarbumi. 2000. Deteksi Dini Kanker Payudara dan Penanggulangannya, Dalam: Deteksi Dini Kanker. Fakultas Kedokteran Universitas Indonesia. Jakarta. 